() Н. В. Менжинська, к.т.н., асистент, Українська академія друкарства, Львів, Україна

\title{
ОСОБЛИВОСТІ ТЕХНОЛОГІЇ ДРУКУ НА ПРИНТЕРАХ ПРЯМИМ ЦИФРОВИМ СПОСОБОМ ПРИ НАНЕСЕННІ ЗОБРАЖЕНЬ НА ТЕКСТИЛЬ
}

\section{Сьогодні при виборі оптимальної технології та пристрою для нанесення зображень враховуються не тільки технічні, а й економічні та екологічні чинники. У новітніх методах друку на тканинах використовують екологічно чисті та якісні основні й допоміжні матеріали, тому надруковані принти стійкі до дії ультрафіолетових променів, відтво- рюються 3 фотографічною якістю, зберігаючи фактуру тканини. У цій статті зроблено огляд сучасної технології друку на текстилі, яка завдяки своїм технологічним й технічним перевагам дає змогу швидко та якісно здійснювати нанесення зображення на текстиль й вироби з нього.}

Ключові слова: цифровий спосіб друку; текстиль; кольорове зображення; якість; принтери для друкування.

\section{Постановка проблеми}

Нині інтенсивно розвивається друк на текстилі. Вирішення завдання вибору конкретного методу нанесення зображення на текстиль та виробів з нього обумовлене застосуванням того чи іншого типу обладнання, видом й споживчими характеристиками тканини, кількістю кольорів майбутнього принта, накладом, економічними розрахунками в цілому та іншими вхідними та вихідними показниками. Науково-технічний прогрес в індустрії цифрового друку на текстилі дає змогу виробникам виготовляти конкурентоспроможну продукцію. У цій статті зроблено огляд технології прямого цифрового друку як од- ного з сучасних та перспективних методів нанесення зображення на текстиль.

\section{Мета роботи}

Зробити огляд технології прямого цифрового друку на текстилі із застосуванням принтерів.

\section{Результати проведених досліджень}

Історія розвитку оздоблення та друкування на текстилі бере свій початок з Китаю, де була знайдена тканина, розфарбована мінеральними барвниками [1]. 3 часом ручне оздоблення тканин замінила вибивна технологія із використанням кольорових штампів та пігментних присипок. У Китаї ж майстри 


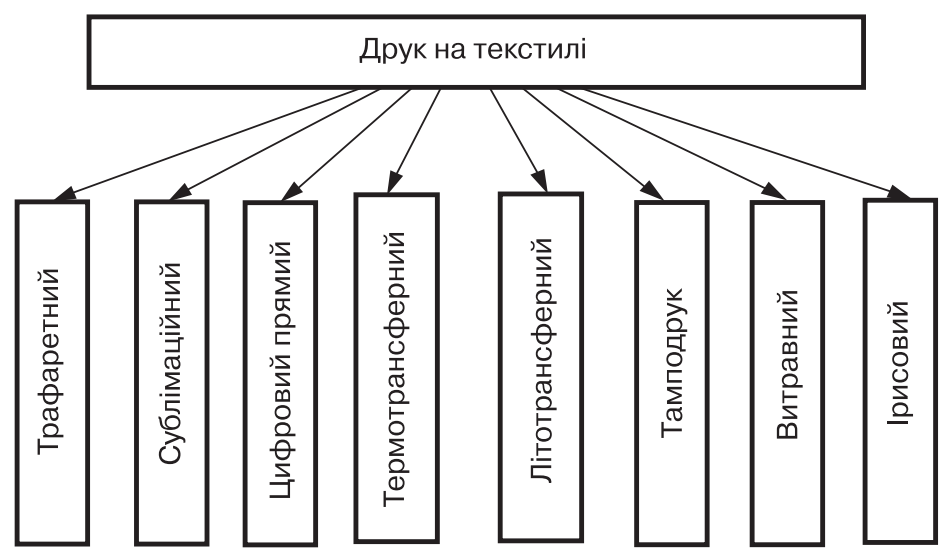

Рис. 1. Методи друку на текстилі та текстильних виробах

не вирізали штампи, а виготовляли трафарети та лекала для нанесення зображення на тканину [2]. Завдяки компанії Tropix Togs (США) у 50-х рр. XX ст. з'явилися перші футболки з надрукованим зображенням. У 1959 р. були розроблені стійкі фарби, що дозволило розширити асортимент оздоблюваних тканин та популяризувати друк на різних текстильних виробах [3].

Аналіз інформаційних джерел доводить, що сьогодні існує досить велика кількість методів друкування на текстилі та текстильних виробах (рис. 1) [4-6].

Хоча цифровий друк $є$ відносно новим сегментом у галузі друку на текстилі, рівень його прогнозованого використання та перспективності на текстильних виробах та тканинах свідчить про те, що найвищий середньорічний приріст буде спостерігатися в Індії - 38,6 \%, Китаї $36,1 \%$, Бразилії - 34,5 \% та Індонезії - 33,6 \% [7].

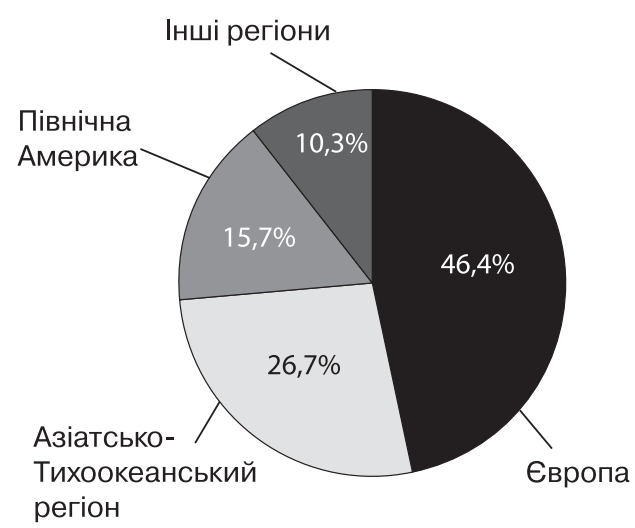

Рис. 2. Розподіл світового ринку за використанням цифрового друку на текстилі 
Діаграма, зображена на рис. 2, демонструє сучасний стан світового ринку цифрового друку на текстилі за використанням у різних регіонах Європи (46,4\%), Азіатсько-Тихоокеанського регіону $26,7 \%$ та ін. [7].

Значне місце в технології цифрового друку відведено методу прямого цифрового друку на принтерах. Завдяки можливості нанесення зображень за низької собівартості при друкуванні малих накладів; високій деталізації зображення; варіації змін у процесі друкування та в цифровому макеті; доступності оздоблення спецефектами; можливості нанесення восьмиколірного зображення з роздільною здатністю від 1400 dpi, спосіб прямого цифрового друку має аргументовані переваги над іншими відомими технологіями друку на тканинах.

Для створення оригінал-макетів застосовують відомі графічні редактори, зокрема, CorelDraw, Adobe Photoshop чи Illustrator з набором передбачених шаблонів. Power RIP для організації перенесення зображення на текстиль дозволяє керувати заданою передачею кольорів на високому професійному рівні.

Для друку на текстилі використовують сучасні принтери, які дають змогу друкувати як на білому, так й на кольоровому текстилі. Основні технічні характеристики принтерів найбільш відомих виробників наведено в табл.

Технічні характеристики принтерів для друку на текстилі

\begin{tabular}{|c|c|c|c|c|c|}
\hline Марка принтера & \begin{tabular}{|c|} 
Макси- \\
мальна \\
роздільна \\
здатність, \\
dрі
\end{tabular} & $\begin{array}{l}\text { Кількість } \\
\text { кольорів }\end{array}$ & Підтримка ОС & $\begin{array}{c}\text { Розмір } \\
\text { друку, см }\end{array}$ & Габарити, мм \\
\hline $\begin{array}{l}\text { Epson SureColor } \\
\text { SC-F2000 5C }\end{array}$ & $1440 \times 1440$ & $\begin{array}{c}5(\mathrm{C} / \mathrm{M} / \mathrm{Y} / \\
\mathrm{Bk} / \mathrm{Wt})\end{array}$ & $\begin{array}{l}\text { Windows } \\
\text { MAC OS X }\end{array}$ & $\begin{array}{c}40,6 \\
\text { (ширина) }\end{array}$ & $985 \times 1425 \times 490$ \\
\hline DTG Digital M2 & $1440 \times 1440$ & $\begin{array}{c}8 \text { (подвійний } \\
\text { СМҮK чи } 4 \\
\text { білих і СМYK) }\end{array}$ & $\begin{array}{l}\text { Windows XP, } \\
\text { Windows } 7 \text {, } \\
\text { Windows } 8\end{array}$ & $61 \times 50$ & $\begin{array}{c}1450 \times 1200 \times \\
\times 880\end{array}$ \\
\hline Interjet $420 \mathrm{C}$ & $2880 \times 1440$ & $\begin{array}{c}8 \text { (модель } \\
\text { кольоропо- } \\
\text { ділу СМҮК } \\
\text { з чотирма } \\
\text { білими) }\end{array}$ & \begin{tabular}{|c|} 
Microsoft \\
Windows \\
98/2000/Me/XP \\
/7/Vista; Mac \\
OS 9.1
\end{tabular} & $42 \times 130$ & $\begin{array}{c}1750 \times 1030 \times \\
\times 1050\end{array}$ \\
\hline FREEJET 300 TX & $1440 \times 1440$ & $\begin{array}{c}\text { CMYK + } \\
\text { 4White }\end{array}$ & $\begin{array}{c}\text { Windows 2000, } \\
\text { XP, Vista, } \\
\text { Windows } 7 / \mathrm{Mac} \\
\text { OSX }\end{array}$ & $31 \times 45$ & $640 \times 1065 \times 460$ \\
\hline FreeJet 500 HS & $1440 \times 720$ & $\begin{array}{l}8 \text { кольорів } \\
\text { CMYK, Lc, } \\
\text { Lm, Lk, LIk }\end{array}$ & \begin{tabular}{|c|} 
Windows 2000, \\
XP, Vista, \\
Windows $7 / \mathrm{Mac}$ \\
OSX
\end{tabular} & $42,5 \times 76,5$ & $1700 \times 900 \times 560$ \\
\hline $\begin{array}{l}\text { PolyprintTexJet } \\
\text { shorTee }\end{array}$ & $1440 \times 1440$ & \begin{tabular}{|c|} 
CMYK / CMYK \\
$+4 x$ White / \\
$2 \times C M Y K$
\end{tabular} & $\begin{array}{c}\text { Mac OS, } \\
\text { Windows XP, } \\
\text { Vista, } 7,8,10\end{array}$ & $27 \times 40$ & $1150 / 660 / 350$ \\
\hline
\end{tabular}


Завдяки впровадженню нових методів та технологій сучасні принтери для друку на текстилі дозволяють відтворювати багатофарбове зображення із максимальною ідентичністю до макета та чіткими контурами. В основу роботи таких принтерів покладено імпульсно-крапельну технологію струминного друку змінного формату. Чорнила для нанесення принтів подаються дозовано п'єзофорсунками з точним позиціонуванням крапель на поверхні тканини [8]. Також відомі такі марки принтерів: Polyprint TexjetPLUS ${ }^{\circledR}$ Advanced, Polyprint TexJet echo, HM 1800-K6.

Суть методу прямого цифрового друку полягає в локальному нанесенні зображення на текстиль без використання проміжного носія. Зображення стійке

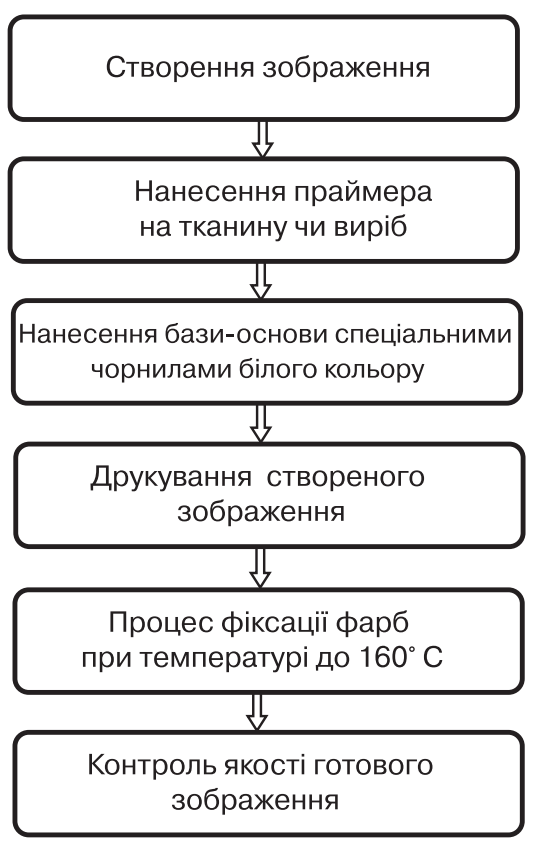

до ультрафіолетових променів. Процес нанесення відбувається пігментними чорнилами на водній основі, які $є$ екологічно безпечними. Такі кольорові чорнила (Cyan, Magenta, Yellow, Black) мають високу криючу здатність. Надрукований принт має досить високий показник насиченості й не піддається розтріскуванню. Цей метод передбачає використання тканин не лише 3 натуральними волокнами, які у своєму складі містять 100 \% бавовну, а й із синтетичних та комбінованих тканин [9].

Специфікою прямого цифрового друку є відмінність між друкуванням на виробах зі світлих та темних тканин: нанесення принта на білу (чи світлу) основу відбувається одразу [10]. Щодо друку на тканинах темних кольорів, то в цьому випадку процес

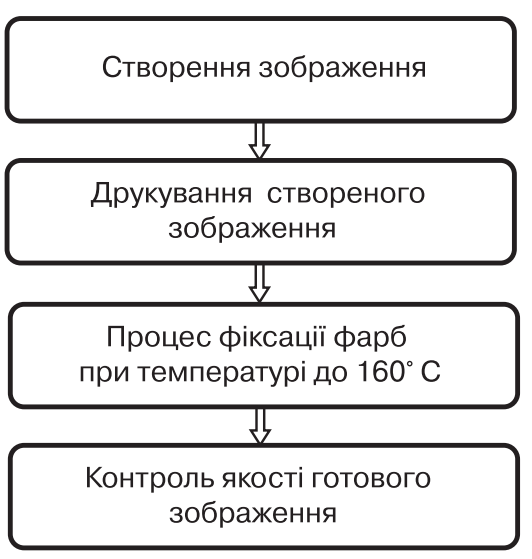

Рис. 3. Узагальнені блок-схеми технологічних операцій при нанесенні зображення на темну (a) та світлу (б) тканину 
нанесення принта відбувається за дещо іншою схемою та має декілька додаткових операцій, які представлено на рис. 3 .

Однією з додаткових операцій може бути пригладження ворсу тканини для покращення закріплення фарб. Встановлено, що чим нижчою $є$ ворсистість тканини та вищий відсотковий вміст натуральних волокон, тим краще відбуватиметься адгезія фарбового зображення до поверхні оздоблюваної тканини. Тривалість термофіксації нанесеного принта залежить від виду обраного матеріалу (процентний вміст штучних, синтетичних чи натуральних волокон), характеру переплетення волокон, поверхневої структури й щільності оздоблюваної тканини, а також від товщини шару нанесеної фарби й може відбуватися протягом 40 с...2 хв. Рівномірність та правильність натягу тканини чи оздоблюваного виробу також впливають на якість друкованого зображення.

\section{Висновки}

У статті зроблено огляд технології цифрового друку на принтерах. Наведено технічні характеристики принтерів та блоксхеми технологічних операцій нанесення зображення на текстильні основи.

\section{Список використаної літератури}

1. Історія розвитку художнього розпису тканин. [Електронний ресурс]. Режим доступу: http://osvita.ua/vnz/reports/culture/11264/.

2. История возникновения печати. Печать на ткани. Часть 3. [Електронний ресурс]. Режим доступу: https://notacard.com.ua/poleznye-stati/114istoriya-vozniknoveniya-pechati-pechat-na-tkani-chast-3.

3. Історія друку на тканині. [Електронний ресурс]. Режим доступу: https://singleprint.com.ua/ua/blog/istoriya-pechati-na-tkani/.

4. Основные виды и способы печати по ткани // КомпьюАрт. 2016. № 4. Режим доступу: https://compuart.ru/article/25250.

5. Как происходит печать на ткани, технологии и особенности. [Електронний ресурс]. Режим доступу: https://www.print-info.ru/articles/pechatna-tkani.html.

6. Яковець І. О. До питання про класифікацію способів нанесення рисунків на текстильні матеріали / І. О. Яковець / Вісник Харківської державної академії дизайну і мистецтв. Мистецтвознавство. Архитектура. 2008. № 12. С. $156-162$.

7. Рост цифровой печати на текстиле в мире // RustmNet - Российские торговые марки. Рынок легкой промышленности. 2016. № 116. Режим доступу: https://rustm.net/catalog/article/2286.html.

8. Репета В. Б. Матеріали і технології цифрового друку / В. Б. Репета, В. В. Шибанов. Л.: Край, 2010. 156 с.

9. Все, що потрібно знати про прямий цифровий друк на тканинах і футболках [Електронний ресурс]. Режим доступу: https://singleprint.com.ua.

10. Що таке прямий цифровий друк на тканину? [Електронний ресурс]. Режим доступу: http://selftex.com/uk/pryamij-tsifrovij-druk. 


\section{References}

1. Istoriia rozvytku khudozhnoho rozpysu tkanyn. Retrieved from http://osvita.ua/vnz/reports/culture/11264/ [in Ukrainian].

2. Istoriya vozniknoveniya pechati. Pechat' na tkani. Chast' 3. Retrieved from http://notacard.com.ua/poleznye-stati/114-istoriya-vozniknoveniyapechati-pechat-na-tkani-chast-3 [in Russian].

3. Istoriia druku na tkanyni. Retrieved from https://singleprint.com.ua/ua/ blog/istoriya-pechati-na-tkani/ [in Ukrainian].

4. (2016). Osnovniye vidy i sposoby pechati po tkani. Journal of KompyuArt, 4. Retrieved from https://compuart.ru/article/25250 [in Russian].

5. Kak proishodit pechat na tkani, tehnologii i osobennosti. Retrieved from https://www.print-info.ru/articles/pechat-na-tkani.html [in Russian].

6. Yakovets, I. O. (2008). Do pytannia pro klasyfikatsiiu sposobiv nanesennia rysunkiv na tekstylni materialy. Journal of Visnyk Harkivskoi derzhavnoi akademii dizainu i mystetstv. Mystetstvoznavstvo. Arhitektura, 12, 156-162 [in Ukrainian].

7. (2016). Rost tsifrovoy pechati na tekstile v mire. Journal of RustmNet Rossiyskie torgovyie marki. Ryinok legkoy promyishlennosti, 116. Retrieved from https://rustm.net/catalog/article/2286.html [in Russian].

8. Repeta, V. B. \& Shybanov, V. V. (2010). Materialy i tehnolohii tsyfrovoho druku. Lviv: Krai, 156 p. [in Ukrainian].

9. Vse, shcho potribno znaty pro priamyi tsyfrovyi druk na tkanynakh i futbolkakh. Retrieved from https://singleprint.com.ua [in Ukrainian].

10. Shcho take priamyi tsyfrovyi druk na tkanynu? Retrieved from https://selftex.com/uk/pryamij-tsifrovij-druk [in Ukrainian].

Сегодня при выборе оптимальной технологии и устройства для нанесения изображений учитываются не только технические, но и экономические, и экологические факторы. В новейших методах печати на тканях используют экологически чистые и качественные основные и вспомогательные материалы, поэтому напечатанные принты устойчивы к воздействию ультрафиолетовых лучей, воспроизводятся с фотографическим качеством, сохраняя фактуру ткани. В данной статье представлен обзор современной технологии печати на текстиле.

Благодаря своим технологическим и техническим преимуществам технология дает возможность быстро и качественно осуществлять нанесение изображения на текстиль и изделия из него.

Ключевые слова: цифровой метод печати; текстиль; цветное изображение; качество, принтеры для печати.

Today when choosing the optimal technology and devices for printing, not only technical, but also economic and ecological factors are taken into account. The latest printing 
methods on fabrics environmentally ecological and highquality basic and auxiliary materials are used. As a result printed prints are resistant to ultraviolet rays, are reproduced with photographic quality, retaining surface textile facture. This article presents an overview of modern printing technology on textiles. Owing to its technological advantages, the technology enables the rapid and high-quality image printing on textile and products from it.

Keywords: digital printing; textile, color image; quality; printers.

Рецензент - О. В. Зоренко, к.т.н., доцент, КПІ ім. Ігоря Сікорського

Надійшла до редакції 24.09.18 